\title{
Frank C. Spencer, MD, FACS, pioneering cardiothoracic surgeon
}

\author{
Richard J. Shemin, MD
}

\author{
From the Division of Cardiac Surgery, Department of Surgery, Cardiovascular Center at UCLA, David Geffen \\ School of Medicine at UCLA, University of California, Los Angeles, Calif. \\ Disclosures: Author has nothing to disclose with regard to commercial support \\ Received for publication Oct 5, 2018; accepted for publication Oct 5, 2018. \\ Address for reprints: Richard J. Shemin, MD, Ronald Reagan UCLA Medical Center, 100 UCLA Medical Plaza, \\ Suite 730, Los Angeles, CA 90095 (E-mail: Rshemin@mednet.ucla.edu). \\ J Thorac Cardiovasc Surg 2019;157:680-3 \\ $0022-5223 / \$ 36.00$ \\ Copyright (c) 2018 by The American Association for Thoracic Surgery \\ https://doi.org/10.1016/j.jtcvs.2018.10.018
}

Cardiothoracic surgeon Frank Cole Spencer, MD, FACS, a past president of the American College of Surgeons (ACS), the American Association for Thoracic Surgery, and the American Surgical Association, died July 23 at age 92 years. Spencer was a distinguished surgeon, patient care advocate, and leader in the surgical community.

Great talent and seminal contributions often spring from motivated individuals whose humble beginnings, extraordinary drive, and exemplary commitment to the pursuit of excellence lead to a career of the highest achievement. Spencer's life and career clearly illustrate these principles and his success.

\section{EARLY LIFE}

Dr Spencer has been quoted as saying, "I thank the good Lord for giving me a good brain, access to good education, and teachers who truly wanted me to succeed." He was born on a farm in rural Haskell County in West Texas. His role model was his paternal grandfather, a physician. The odds were against this boy who attended a 2-room schoolhouse even going to college. His parents' determination to provide education and opportunity and a high school science teacher with a talent for fueling curiosity helped make his dreams into reality.

\section{EDUCATION}

Spencer entered North Texas State College, in Denton, Tex, at age 15 years. A great teacher and mentor, James L. Carrico, PhD, chair of the Department of Chemistry, recognized great potential in Spencer and chose him as laboratory assistant. Spencer recalled that Dr Carrico instilled "the students with the excitement of learning and a warm paternalism, virtually adopting them as foster children." Dr Carrico's mentorship, combined with an innate desire for excellence and a farming background, made Spencer

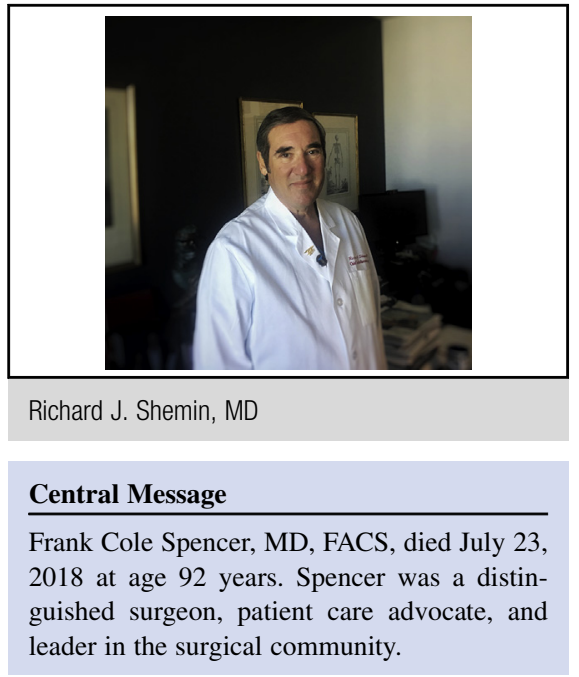

"an incurable workaholic." He learned the importance of mentorship and teaching. These became featured elements throughout his career.

Dr Spencer entered Vanderbilt School of Medicine at age 17 years. Surgery beckoned him. He was a member of the Alpha Omega Alpha Honor Medical Society and graduated at the top of his class. He went on to complete an internship under Alfred Blalock, MD, FACS, at Johns Hopkins

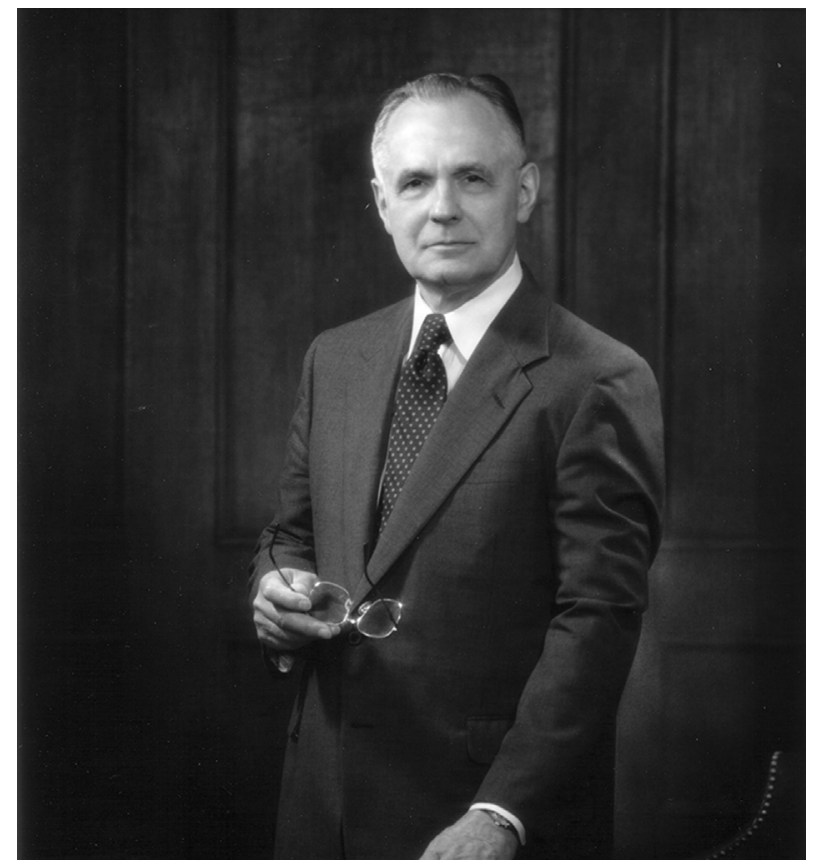


Hospital, Baltimore, Md, where pioneering work was being performed in the new field of cardiac surgery. At Hopkins, he was surrounded by an incredible collection of talented residents and faculty who were working with Dr Blalock at this pivotal time.

\section{MILITARY SERVICE AND SURGICAL INNOVATION}

After his internship year, Spencer accompanied William Longmire, MD, FACS, to the University of California, Los Angeles (UCLA), to work within the new Department of Surgery. He worked in clinic and in the laboratory with William Muller, MD, FACS, and James Maloney, MD, FACS. However, he left UCLA to serve in the US Navy Medical Corp (1951-1953) during the Korean War.

Dr Spencer's interest, curiosity, and dedication to patients were a constant theme throughout his career. As a young surgeon at Hopkins and UCLA, he had learned how to repair arteries. Spencer was disappointed with the existing standard of vessel ligation and amputation as the treatment for arterial injury to the leg that had been the treatment of choice since World War II because of the often-long delay from injury to surgical treatment. In Korea, Mobile Army Surgical Hospital units allowed early evacuation by helicopter, leading to the opportunity for a change in practice and the performance of early arterial repair.

Seeking permission from authorities to attempt repair of injured vessels on a trial basis and not receiving a response, he started to perform the procedure in his Mobile Army Surgical Hospital unit. He faced court martial for performing repair of arterial injuries to avoid leg amputation. During the next 9 months, more than 150 repairs were performed with an $80 \%$ to $90 \%$ success rate. The results were published in the Annals of Surgery. ${ }^{2}$

Spencer remarked, "I could not live with myself if I was forced to take someone's leg off when it was not necessary." Instead of court martial, Spencer received the Legion of Merit Award, which led to national recognition. "I became a boy hero, much to my embarrassment...but arterial repair in Korea benefited more people than anything I've ever done." It is not surprising that his ACS Presidential Address in 1990 was titled "The Vital Role in Medicine of Commitment to the Patient." 3

\section{ACADEMIC CAREER}

After discharge from the US Navy, he returned to Johns Hopkins to complete his surgical residency under Dr Blalock. The Hopkins years included 6 years on the faculty where he matured into an innovative surgeon, a gifted teacher, and a mentor to students and resident physicians. These years were among the most innovative and exciting in the development of the field of cardiac surgery.

In 1961, Benjamin Eiseman, MD, FACS, recruited Spencer to become professor of surgery at the University of Kentucky, Lexington. Five years later, Spencer accepted the position of the George David Stewart Professor and Chairman, Department of Surgery, at New York University (NYU) School of Medicine, New York, NY. He served in that capacity for 32 years, establishing what is among the great surgical departments in terms of clinical volume, innovative research, and superb residency training. From

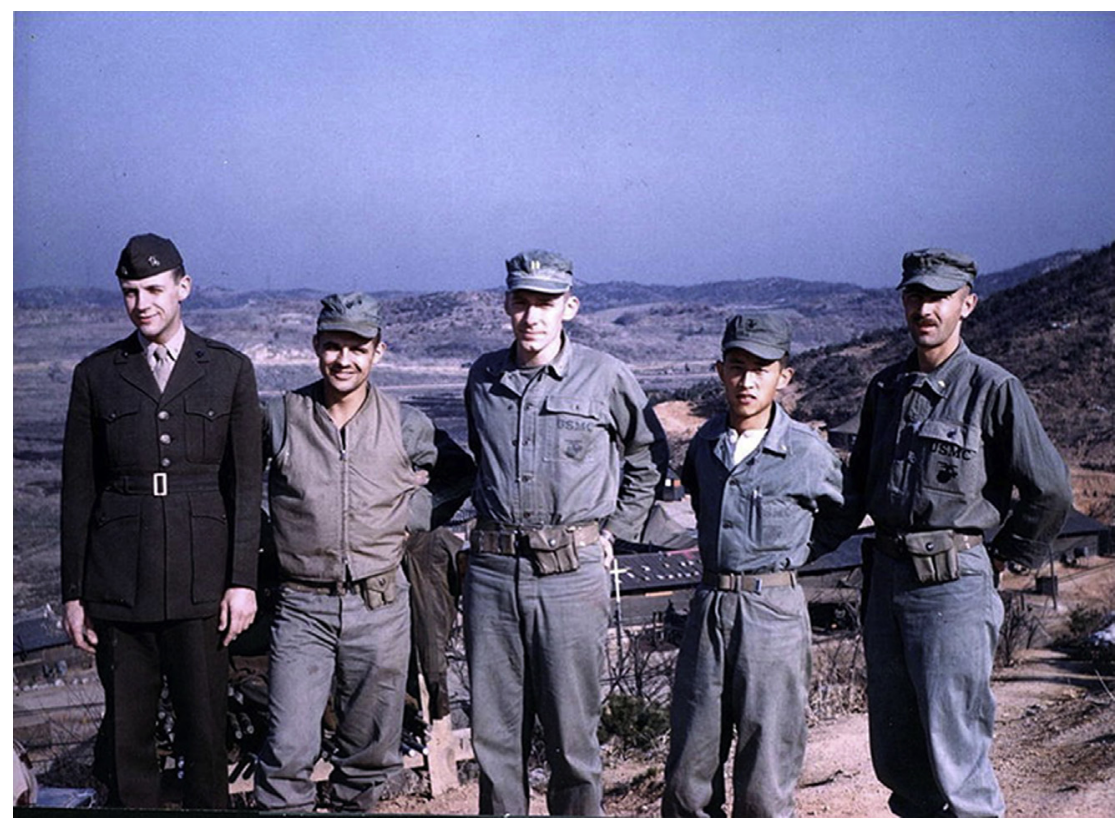


2002 until shortly before his death, Spencer remained active at his beloved NYU as chairman of clinical facilities and development and director of patient safety.

Spencer's wise counsel and leadership resulted in his election to high office in several professional organizations in American surgery. Before serving as ACS President (1990-1991), Spencer was an ACS Regent, serving as Chair (1987-1989) and as a member of the Board of Regents (1980-1989). Other ACS leadership positions in which he served are as follows: Chair, Ad Hoc Committee on Professional Liability (1982-1986); Chair, Scholarships Committee (1984-1987); Chair, Central Judiciary Committee (1985-1987); and Chair and Consultant, Committee on Patient Safety and Quality Improvement (1986-1996 and 1998-2012, respectively). In 1979, he delivered the John H. Gibbon, Jr, Lecture at the ACS Clinical Congress. ${ }^{4} \mathrm{He}$ was president of the Society of Clinical Surgery (19741975), New York Surgical Society (1976), Johns Hopkins Medical and Surgical Association (1994-1975), New York Center for Liver Transplantation (1994), American Association for Thoracic Surgery (1982-1983), and American Surgical Association (1997-1998).

\section{A MASTER SURGEON AND TEACHER}

Spencer never forgot his Texas roots and dedication to each patient. He never delegated postoperative care to others. His clinical rounds were legendary for their attention to detail and logical scientific problem solving. His morbidity and mortality conferences were unparalleled; faculty and former resident physicians have vivid memories of respect and occasional fear of those hours during which we were taught to understand outcomes, medical and technical errors of omission or commission, and knowledge gaps long before these concepts became formalized in practice-based learning. Resident physicians and faculty always were professional and prepared in his presence. His clinical judgment, experience, and knowledge of the medical literature were always current and innovative.

In the operating room, Spencer was a master surgeon. His dedication to detail and compulsive recording of observations, which he later reviewed, allowed him to discover patterns that remained obscure to others. He always pushed the envelope to advance the safety and range of surgical treatments. He pursued perfection, teamwork, and communication. He demanded focused decorum during operations.

The advances in the field of surgery for coronary artery disease, valvular heart disease, myocardial preservation, mitral valve repair, and safe cardiopulmonary bypass are, in part, due to his direct efforts or the efforts of those whom he stimulated to pursue these areas. For example, he sent George E. Green, MD, FACS, to the laboratory to investigate the use of the internal thoracic artery as a bypass conduit, an idea that Spencer himself investigated during his years at the University of Kentucky. He sent O. Wayne
Isom, MD, FACS, to work with Sir Bryan Barratt Boyes in New Zealand to bring his innovative surgical experience in congenital cardiac surgery to NYU. He was an early supporter of Gerald Buckberg, MD, FACS, and an early adopter of the clinical use of blood cardioplegia for myocardial protection. He sent Steven Colvin, MD, FACS, to Paris, France, to learn new approaches to mitral valve repair from Alain Carpentier, MD, PhD. He encouraged Joseph Cunningham, $\mathrm{MD}, \mathrm{FACS}$, to investigate spinal cord protection during descending thoracic aortic surgery.

Spencer understood the value of both basic and clinical research. He understood the power of large clinical databases and their contribution to outcomes research. He was a champion of the standard use of binocular magnifying loupes to perform coronary artery surgery.

Spencer wrote more than 350 peer-reviewed articles and 38 book chapters or books. Most notably, he was the coeditor of the annual Yearbook of Surgery from 1971 to 1991, and a contributor to Vascular Trauma and Surgery of the Chest (fifth and sixth editions), and he was a founding editor of Schwartz's Principles of Surgery. Spencer lectured worldwide as a visiting professor.

In 1997, he received the American Heart Association Achievement in Cardiovascular Science and Medicine Award. In 2010, The American Association for Thoracic Surgery bestowed its Lifetime Achievement Award to Spencer for "Outstanding contributions to cardiothoracic surgery that have left an indelible mark for future generations."

Among all these achievements, awards, and professional recognition, Spencer derived his greatest pride from teaching and witnessing the achievement of his medical students, residents, and fellows. The Hopkins traditions of clinical excellence, teaching, research, and leadership were the hallmarks of the NYU surgical experience. Spencer was legendary for memorizing the face, name, and a brief biography of every intern. He influenced the careers of hundreds of young surgeons, many of whom became department chairs and leaders in surgery in the United States and abroad. He received the NYU School of Medicine Distinguished Teacher Award in 1969, 1970, and 1977, and the Torch of Learning Award from the American Friends of the Hebrew University in 1976.

\section{THE JOY OF SURGERY}

Spencer taught the basic principles of surgery and how to be a physician, surgeon, and humanitarian. First and foremost, he admonished, "Do what is best for the patient." This precept was epitomized in his career when he knew arterial repair was feasible and better than ligation. He boldly faced court martial while saving limbs, and eventually he changed military surgical policy. His second principle was, "Don't be smart enough to quit." This statement stemmed from a belief that complex surgical problems 
often have a cause often so difficult to figure out that most would give up. Spencer taught that persistence and using the scientific method with experimentation would eventually lead to solutions. "Surgery is a joy and the pleasure of a surgical career stems from several basic instincts. First is the deep instinctive personal pleasure in helping a sick person get better. Second is the excitement of intellectual productivity, the discovery of new knowledge, and the scientific basis of our profession. Third, is the pleasure of teaching, a vital [component] of the medical profession since the time of Hippocrates." Finally, "Unique to surgery is the creative use of one's hands to cure or improve human disease." His comments are timeless. Despite occasional failures, a surgeon's optimism, excitement, and pragmatic resourcefulness remain his or her strength throughout a career of seeking surgical solutions to complex problems.

Spencer's career spanned more than 4 decades. His contributions to general and vascular surgery, cardiac surgery, health policy, and surgical art and science are innumerable. His surgical expertise has saved tens of thousands of lives and relieved suffering. His influence on patient care will continue in practice by the hundreds of practicing surgeons he trained and guided. Clearly, he stands among the giants of surgery in the 20th century. His influence will be longlived through his students, resident physicians, and colleagues. I am indebted to him as my teacher, mentor, role model, and advisor.

His attitude about the future of medicine stood in contrast to the gloom and doom of others. "I remain as enthusiastic and excited about the pleasures and opportunities of surgery and medicine as in my early house officer days. My attitude is a blend of confident optimism with pragmatic realism."

We celebrate Dr Spencer's life and career. We mourn his loss. We have lost a giant in surgery, and a friend.

\section{References}

1. Shemin RJ. Lifetime Achievement Award: Frank Cole Spencer, MD. J Thorac Cardiovasc Surg. 2010;139:1-3.

2. Spencer FC, Grewe RV. The management of arterial injuries in battle casualties Ann Surg. 1955;141:304-13.

3. Spencer F. Presidential address: the vital role in medicine of commitment to the patient. Bull Am Coll Surg. 1990;75:6-19.

4. Spencer FC. The Gibbon Lecture: competence and compassion: two qualities of surgical excellence. Bull Am Coll Surg. 1979;64:15-22. 